\title{
Secalonic acid- F inhibited cell growth more effectively than 5-fluorouracil on hepatocellular carcinoma in vitro and in vivo
}

\author{
X. GAO ${ }^{1,2}$, H. L. SUN ${ }^{1,2}$, D. S. LIU ${ }^{1,2, *}$, J. R. ZHANG ${ }^{1,2}$, J. ZHANG ${ }^{1,2}$, M. M. YAN ${ }^{1,2}$, X.H. PAN ${ }^{1,2, *}$ \\ ${ }^{1}$ Department of Pharmaceutical Sciences, Binzhou Medical University, Yantai, China; ${ }^{2}$ The Key Laboratory of Traditional Chinese Medicine \\ Prescription Effect and Clinical Evaluation of State Administration of Traditional Chinese Medicine, Yantai, China
}

*Correspondence:panxh_2008@126.com,desheng_liu@sina.com

Received May 27, 2016 / Accepted October 28, 2016

\begin{abstract}
Hepatocellular carcinoma (HCC), one of the most common types of liver cancer, could be treated with 5-fluorouracil (5-FU). Due to its side effects, 5-FU is more often used as the co-administration drug in clinical practice. Secalonic acid-F (SAF), isolated from a fungal strain identified in our lab as Aspergillus aculeatus, showed potent biological activities. The goal of this study was to evaluate the inhibitory effects of SAF on hepatocellular carcinoma and to compare it with that of 5-FU. Results showed that SAF effectively inhibited cell growth with a dose-dependent manner in vitro and in vivo. And the inhibitory effects of SAF were stronger than that of 5-FU. Importantly, the cytotoxicity of SAF to peripheral blood mononuclear cells (PBMC) was similar to that of 5-FU. Furthermore, this study demonstrated that SAF arrested the cell cycle at the G1 phase and induced apoptosis with a dose-dependent manner by activating caspase 3 and caspase 9 through a mitochondrial pathway. Consequently, SAF may be a better potential candidate compound for human cancer treatment; these results will afford more data for antitumor agent design in detail.
\end{abstract}

Key words: Secalonic acid-F, 5-fluorouracil, tumor growth, PBMCs, cell cycle, apoptosis

There are two major types of liver cancer, primary liver cancer and metastasis-related liver cancer. HCC is the most common type of primary liver cancer for the adult $[1,2]$. It is the third leading cause of cancer-related death worldwide [3]. Chemotherapy is widely performed in treating patients who are diagnosed with HCC. Among all the chemotherapeutic agents, 5-FU is one of the commonly applied ones in the clinical practice [4]. Inside the cells, 5-FU can be biotransformed into several cytotoxic metabolites, and it can induce cell cycle arrest and lead to apoptosis. However, 5-FU monotherapy is not so effective, people with HCC can easily develop drug resistance after long terms of medication [5]. Consequently, there is an urgent need to develop more novel antitumor agents for HCC clinical therapy.

During the past few years, Secalonic acid-F (SAF) has been isolated from several sources with different promising biological effects $[6,7]$. Previously, a fungal strain from sediment samples which was collected in the coastal saline in the Yellow River Delta in China, was identified as Aspergillus aculeatus. After fermentation, SAF was purified from the crude extract as a yellow powder [8]. Up to now, it is still an unexplored field about the effects and mechanisms of SAF on hepatocellular carcinoma. It's also a wonderful imagine whether SAF can possess hepatocellular carcinoma growth inhibition in vitro or in vivo with a potency similar to that of 5-FU or not. In this paper, SAF was assessed for the antitumor activities on hepatocellular carcinoma in vitro and in vivo, while 5-FU being used as a positive control. Furthermore, additional details of SAF were investigated in this research concerning the cytotoxicities of SAF and 5-FU to peripheral blood mononuclear cells (PBMC), the cell cycle and apoptosis. Together, our findings indicated that SAF may be a promising antitumor agent for tumor clinical treatments or assistant treatments.

\section{Materials and methods}

Chemicals, reagents and antibodies. SAF was dissolved in dimethyl sulfoxide (DMSO) at $0.1 \mathrm{mM}$ stock solution and stored at $-20{ }^{\circ} \mathrm{C}$. 3-(4, 5-dimethylthiazol-2-yl)-2, 5-diphenyltetrazolium bromide (MTT) and DMSO were obtained from Sigma-Aldrich (Sigma, USA). DMEM liquid media was a product of Gibco BRL (Gaitherbrug, MD). Cell cycle assay 
kit and apoptosis assay kit were purchased from KeyGEN BioTECH (Nanjing, China). Antibodies for rabbit anti-human cl-caspase3 $(17 \mathrm{kD}, 19 \mathrm{kD})$, cl-caspase9 $(37 \mathrm{kD})$, cytochrome $\mathrm{C}(14 \mathrm{kD})$ and $\mathrm{GAPDH}(37 \mathrm{kD})$ as well as the anti-rabbit IgG HRP-conjugated secondary antibody were all bought from Cell Signaling Technology (Beverly, MA, USA).

Cell culture. Human hepatocellular carcinoma cells designated $\mathrm{HepG}_{2}$ were propagated in Dulbecco's modified Eagle's medium (DMEM) medium supplemented with fetal bovine serum $(10 \%)$. Cells were incubated at $37^{\circ} \mathrm{C}$ in a humidified atmosphere composed of $95 \%$ air and $5 \% \mathrm{CO}_{2}$. Cell density was adjusted every two days with $0.25 \%(\mathrm{~m} / \mathrm{v})$ trypsin and $0.02 \%$ $(\mathrm{m} / \mathrm{v})$ ethylenediaminetetraacetic acid (EDTA).

Cell viability assay. Cell viability was determined by MTT assay. Cells (4000 cells per well) were cultured in a 96-well plate. After a certain period incubation, increasing concentrations $(0-50 \mu \mathrm{M})$ of SAF or 5-FU $(10 \mu \mathrm{M})$ were added and incubation was carried out for 24,48 and $72 \mathrm{~h}$. Afterwards, MTT (5 mg/ml in PBS) was added to each well, and cells were incubated for additional $4 \mathrm{~h}$ at $37^{\circ} \mathrm{C}$. The supernatants were removed carefully and $100 \mu \mathrm{l}$ of DMSO was added to solve crystal. The absorbance values were recorded using a Microplate Reader (ELX800, Bio-Rad, USA) at $490 \mathrm{~nm}$. DMSO was used as the solvent control agent. The $\mathrm{IC}_{50}$ values were calculated with GraphPad Prism software (GraphPad Software, Inc).

Cellular morphology observation. HepG2 cells were seeded in a 24-well plate at a density of 2000 cells per well. After $12 \mathrm{~h}$ incubation, cells were treated with SAF at 5, 10 and $20 \mu \mathrm{M}$ concentrations for 48 and $72 \mathrm{~h}$. The cellular morphology was observed with the inverted microscope.

Cell cycle assay. To investigate the effect of SAF on the cell cycle distribution, HepG2 cells were seeded in a 6-well culture plate at a density of $2 \times 10^{4}$ cells per well. After adhesion, the medium was replaced with a fresh medium containing SAF at 5, 10 and $20 \mu \mathrm{M}$. After $48 \mathrm{~h}$ incubation, the cells were harvested and fixed with $70 \%$ cold ethanol overnight. Cells were then treated with a Cell Cycle Assay Kit according to the manufacturer's instructions, and the cell cycle was analysed by a flow cytometer (BD FACS Canto ${ }^{\mathrm{TM}}$, BD Biosciences, San Jose, USA).

Apoptosis assay. HepG2 cells were seeded in a 6-well culture plate at a density of $2 \times 10^{4}$ cells per well. After $24 \mathrm{~h}$ incubation, the medium was replaced with a fresh medium containing SAF $(10 \mu \mathrm{M})$ to treat additional 24,48 and $72 \mathrm{~h}$. The cells were harvested and incubated with AnnexinV-FITC and propidium iodide (PI) dyes successively from Apoptosis Assay Kit according to the manufacturer's instructions. Apoptotic rates of cells were analysed by a flow cytometer.

Mitochondrial membrane potential analysis. Mitochondrial membrane potential $(\Delta \Psi \mathrm{m})$ was evaluated by the confocal microscopy with JC-1 (5,5',6,6'-tetrachloro-1,1'3,3'tetraechylbenzimidazolylcarbocyanine iodide). J-aggregates in intact mitochondria fluorescent red with emission at 590 $\mathrm{nm}$ expressed higher membrane potential, and J-monomers in the cytoplasm fluorescent green with emission at $529 \mathrm{~nm}$ expressed lower membrane potential. JC-1 $(10 \mu \mathrm{M})$ was added to the cells and the cells were incubated at $37^{\circ} \mathrm{C}$ for $15 \mathrm{~min}$ in the dark. Then the cells were washed twice with PBS and identified using the confocal microscopy. CCCP $(10 \mu \mathrm{M})$ was used as the positive control.

Preparation of cell lysates and western blot analysis. Cells were lysed with RIPA buffer for $30 \mathrm{~min}$ on ice, and the lysates were separated $12 \%$ SDS polyacrylamide gel electrophoresis (SDS-PAGE). The proteins were transferred to a PVDF membrane (Millipore, Billerica, MA, USA) and membrane was blocked in $5 \%$ non-fat dried milk for $1 \mathrm{~h}$. The membrane was incubated with specific primary antibodies at $4{ }^{\circ} \mathrm{C}$ overnight, then exposed to respective HRP-conjugated secondary antibodies for $1 \mathrm{~h}$ at room temperature. Immunoreactive bands were visualized using ECL reagents and an enhanced chemiluminescence detection system (Amersham-Pharmacia Biotech). GAPDH was used as the loading control.

Tumorigenicity analysis in vivo. All animal experiments performed in this study were compliant with the national and international guidelines, and mice were cultured in the Animal Ethics Committee of Binzhou Medical University. Mouse H22 hepatocarcinoma cells were maintained in the peritoneal cavity of male BALB/c mice as described [9]. Male BALB/c mice aged four weeks were used and $\mathrm{H} 22$ cells which were usually to establish murine solid tumor model were performed. H22 cells were suspended with normal saline and each mouse was injected with $5 \times 10^{5}$ cells to create ascites intraperitoneally (IP). H22 tumor ascites were axillary vaccination to mice with $0.1 \mathrm{ml} / 10 \mathrm{~g}$. After seven days, mice were treated with various concentrations of SAF and 5-FU every day with gastric infusion. Tumor volumes and weights were measured every day. At the end of the experiment, mice were sacrificed, and the cancer chunks were collected. Five mice were used for each experimental group and control group.

To investigate the inhibition of SAF on the progression of cancer in mice, animals' thymuses and spleens were weighted after execution. We calculated the indexes of the thymus and the spleen. The related formula was as follows:

Organ index $(100 \%)=[$ organ's weight $(g) /$ body weight $(g)] \times 100$

Human cell viability analysis. Peripheral blood mononuclear cells (PBMCs) were collected from heparinized blood of ten healthy human volunteers (aged 18-20 years old) according to the agreement by the Ethics Committee in Binzhou Medical University Hospital. Cells were isolated by density gradient centrifugation (Lymphocyte Separation Medium, Solarbio, China). PBMCs were seeded in a 96-well plate at a concentration of $5 \times 10^{4}$ cells per well and cultured with several concentrations of SAF and 5-FU. At the end of the culture, cytotoxic analyses were performed against PBMCs using MTT assay.

Statistical analysis. All tests were repeated at least three times. Data (mean $\pm \mathrm{SD}$ ) and student's $t$-test were carried out with the GraphPad Prism software. ${ }^{\star} P<0.05,{ }^{* \star} P<0.01$ or ${ }^{* * *} P<0.001$ were considered indications of the statistically significant results. 

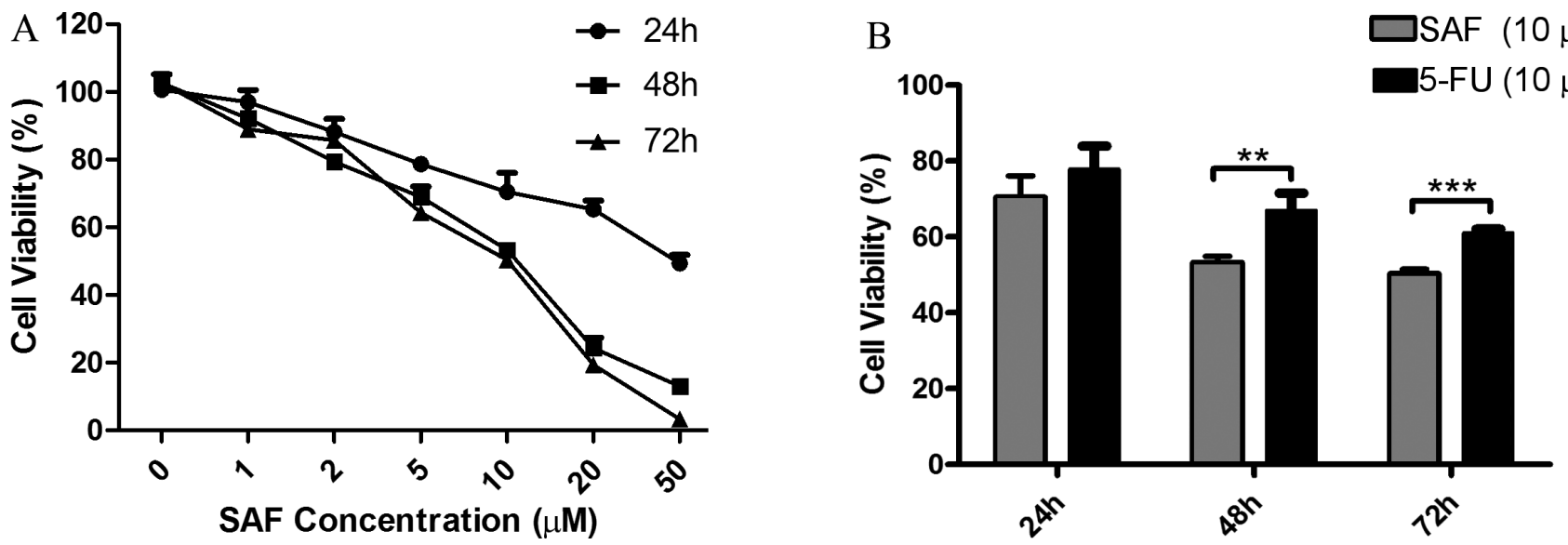

Figure 1. SAF inhibited cell viability with a time- and concentration-dependent manner, and the inhibitory effect of SAF was more potent than that of 5 -FU in vitro. (A) HepG2 cells were treated with various concentrations of SAF for 24,48 and $72 \mathrm{~h}$. (B) HepG2 cells were treated at $10 \mu \mathrm{M} \mathrm{SAF}$ or $10 \mu \mathrm{M} 5$-FU for 24,48 and $72 \mathrm{~h}$. The results were mean $\pm \mathrm{SD}\left(n=8\right.$ wells) of three independent experiments. ${ }^{\star \star} P<0.01,{ }^{\star * \star} P<0.001$ compared with control.

\section{Results}

SAF concentration-dependently inhibited cell viability in vitro, and its effect was more potent than that of FU-5. First, to explore the inhibitory effect of SAF in vitro, the HepG2 human hepatocellular carcinoma cell line was used. The cells were treated with various concentrations $(0-50 \mu \mathrm{M})$ of SAF for 24, 48 and $72 \mathrm{~h}$, and the antiproliferative activity of SAF was investigated by MTT assay. SAF caused a significant decrease in cell viability with a time- and concentration-dependent manner (Figure 1A). The $\mathrm{IC}_{50}$ values of HepG2 cells were $45.49 \pm 2.65,8.73 \pm 1.16$ and $7.66 \pm 0.59 \mu \mathrm{M}$ for 24,48 and $72 \mathrm{~h}$, respectively. Next, the inhibitory effect of cell viability by SAF $(10 \mu \mathrm{M})$ was compared with that of 5 -FU $(10 \mu \mathrm{M})$. It is also important to note that SAF inhibited cell viability more effective than that of 5 -FU on a $10 \mu \mathrm{M}$ concentration for 48 and $72 \mathrm{~h}$, respectively. (Figure $1 \mathrm{~B}$ ).

SAF effectively suppressed tumor growth with a concentration-dependent manner in vivo, and its effect was more potent than that of 5-FU. To investigate the inhibitory effect of SAF in vivo, we firstly used a mice xenograft model. Twenty-five SPF grade BALB/c mice were used, and each group contained five mice. Eleven days after the treatment, all mice were sacrificed, and their tissues were dissected and weighed. It was clear that the tumor weights had significantly decreased with a concentration-dependent manner with SAF treatment (Figure 2A, 2B). The tumor growth inhibition rates were $56.72 \pm 6.86 \%$ (10 mg/kg), $84.66 \pm 2.88 \%(20 \mathrm{mg} /$ $\mathrm{kg})$ and $95.70 \pm 1.91 \%(50 \mathrm{mg} / \mathrm{kg})$, respectively. Importantly, the tumor growth inhibition rate of 5 -FU group $(50 \mathrm{mg} / \mathrm{kg})$ was $71.45 \pm 7.38 \%$. The tumor weights of the SAF treatment group were obviously lower than that of 5-FU control group on the same concentration (Figure 2A, 2B). Data confirmed that tumor inhibitory effect of SAF was more potent than that of $5-\mathrm{FU}$ in vivo.
Cancer usually affects the body's immune system especially the thymus and the spleen. Consequently, the relative weights of the mice's thymuses and spleens were analysed. A different concentration administration of SAF made a significant decrease in the index of the spleen weights; however, there was no marked difference between SAF (50 mg/kg) and 5-FU (50 $\mathrm{mg} / \mathrm{kg}$ ). In contrast, the weights of the thymuses did not show a regular pattern in the SAF groups (Figure $2 \mathrm{C}$ ). However, SAF appeared as an augment effect on the thymus index, in contrast to the effect of 5-FU on the same concentration (Figure 2D).

Furthermore, we analysed cell viability inhibitory rates of SAF and 5-FU to PBMCs. Compared to the control group, which had no cytotoxic effects, the exposures of PBMCs to SAF and 5-FU showed no significant reductions on cell viability. And there were no statistical differences on the cell viability inhibitory rates between SAF group and 5-FU group (Figure 2E).

SAF arrested the cell cycle at the G1 phase and induced apoptosis in HepG2 cells. Disturbance of cancer cell cycle is related to cell growth and apoptosis. To detect whether or not the cell growth inhibitory effect of SAF was associated with the cell cycle arrest, a flow cytometer was used to measure cell cycle distribution in HpeG2 cells. The cells were treated with 5, 10 and $20 \mu \mathrm{M} \mathrm{SAF}$ for $48 \mathrm{~h}$; as a result, SAF induced a G1 phase arrest in HepG2 cells (Figure 3A). Compared to the G1 phase arrest, the $\mathrm{S}$ phase shortened obviously, while the G2 phase experienced no change. These results suggested that SAF might inhibit cell growth by mediating cell cycle arrest.

Through a microscope, the cytotoxic effect of SAF was observed in HepG2 cells. The cells were cultured with SAF $(5,10$ and $20 \mu \mathrm{M})$ for 48 and $72 \mathrm{~h}$. There were significantly more death cells with a higher concentration of SAF (Figure 3B). Next, to explore the mechanism of SAF on cytotoxicity, an apoptosis analysis was performed by a flow cytometer. The percentage of apoptotic cells increased after exposure 

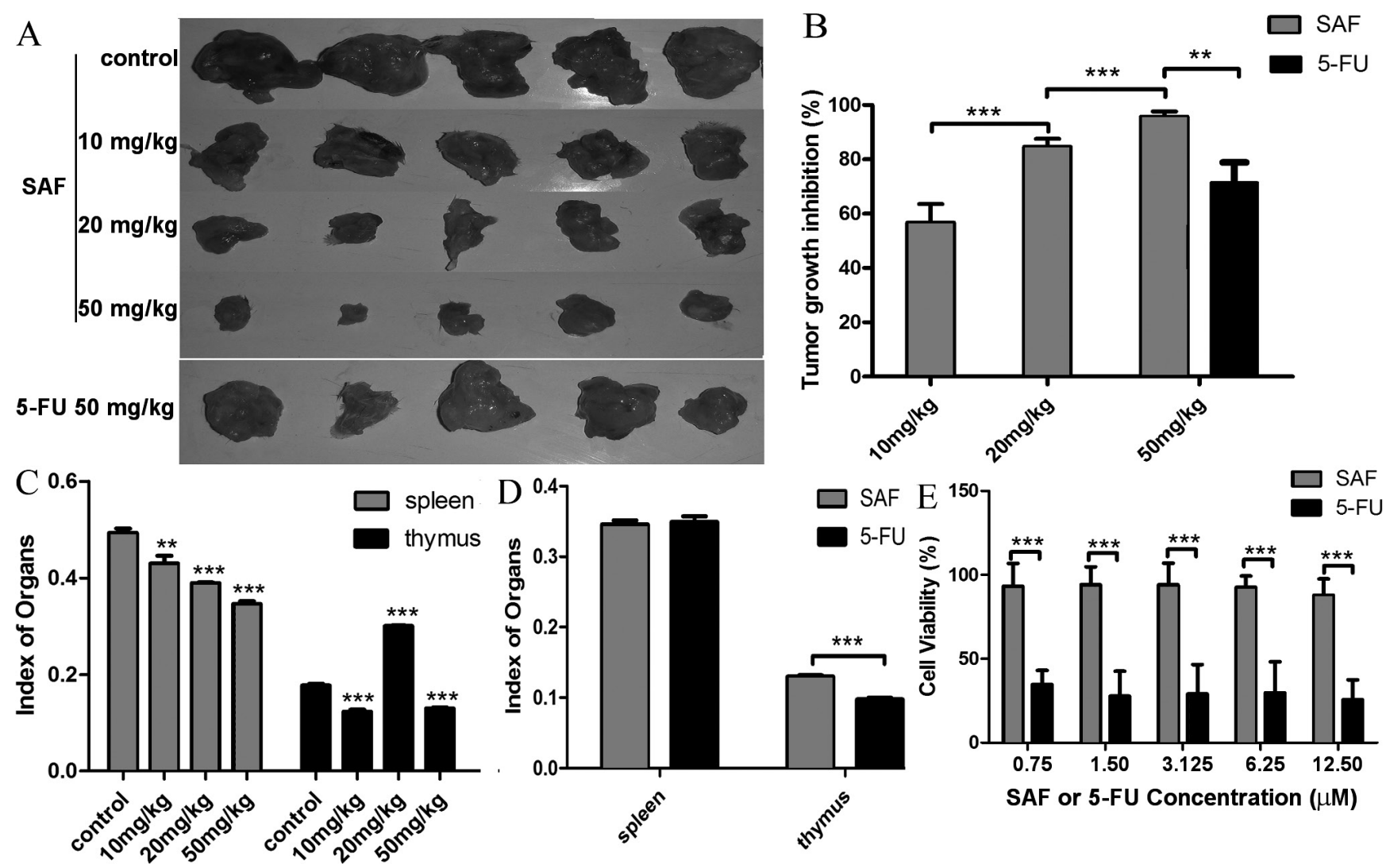

SAF or 5-FU Concentration $(\mu \mathrm{M})$

Figure 2. SAF inhibited tumor growth with a concentration-dependent manner, and the inhibitory effect of SAF was more potent than that of 5-FU in vivo. (A, B) Mice were sacrificed after treatment with several concentrations of SAF for eleven days. The tumor weights were quantified. The effect of SAF $(50 \mathrm{mg} / \mathrm{kg})$ on tumor growth inhibition was compared with that of $5-\mathrm{FU}(50 \mathrm{mg} / \mathrm{kg})$. (C) The effects of SAF on relative weights of thymuses and spleens were quantified. (D) The effects of SAF $(50 \mathrm{mg} / \mathrm{kg}$ ) on the index of organs were compared with that of 5-FU (50 mg/kg). (E) The cytotoxicities of SAF and 5-FU were analysed to PBMCs using MTT assay. ${ }^{* *} P<0.01,{ }^{* *} P<0.001$ were considered statistically significant.

to $10 \mu \mathrm{M} \mathrm{SAF}$ for 24,48 and $72 \mathrm{~h}$. The results showed that $\mathrm{SAF}$ at $10 \mu \mathrm{M}$ induced apoptotic rates (the early-stage apoptotic rate plus the late-stage apoptotic rate) as $22.13 \pm 1.73 \%$, $61.07 \pm 1.81 \%$ and $85.30 \pm 3.76 \%$ for 24,48 and $72 \mathrm{~h}$, respectively (Figure 3C, 3D).

SAF induced apoptosis by activating caspase 3 and caspase 9 through a mitochondrial pathway. In order to investigate the mechanisms of SAF on apoptosis in HpeG2 cells, lipophilic dye JC-1 was adopted (it can accumulate in the mitochondria), to indicate the dissipation of mitochondrial membrane potential. As shown in Figure 4A, J-aggregates, which show red fluorescence for high membrane potential, decreased with a concentration-dependent manner with SAF treatments. Conversely, J-monomers, which show green fluorescence for lower membrane potential, increased with SAF treatments (Fig4. A). CCCP $(10 \mu \mathrm{M})$ was used as a positive control in this study. Also the expression of cytochrome c increased with SAF treatments (Figure 4B, 4C). Furthermore, the results showed that SAF induced apoptosis by activating caspase 3 and caspase 9 genes, and their cleavage fragments (cl-caspase3 and cl-caspase9) increased with SAF treatments
(Figure 4D-F). These data demonstrated that SAF induced apoptosis through a mitochondrial pathway.

\section{Discussion}

Hepatocellular carcinoma (HCC) is one of the most common lethal cancers in the world. Today, the growing new cases of HCC are nearly equal to the number of deaths from this disease, and HCC has become the third leading cause of cancer related to death in men [10-12]. Although there have been a variety of ways to treat liver cancer, chemotherapy is still the major method currently used to prolong the survival of patients with HCC, despite the severe adverse reactions [13, 14]. 5-FU is a commonly used agent for liver cancer in clinical treatments in combination with other therapeutics. However, there were many problems with 5-FU clinical application [1518]. In fact, there is still no special effective agents for liver cancer therapy.

Fungi derived from unique environments have attracted great attention since they have developed unique metabolic and physiological capabilities which not only ensure 

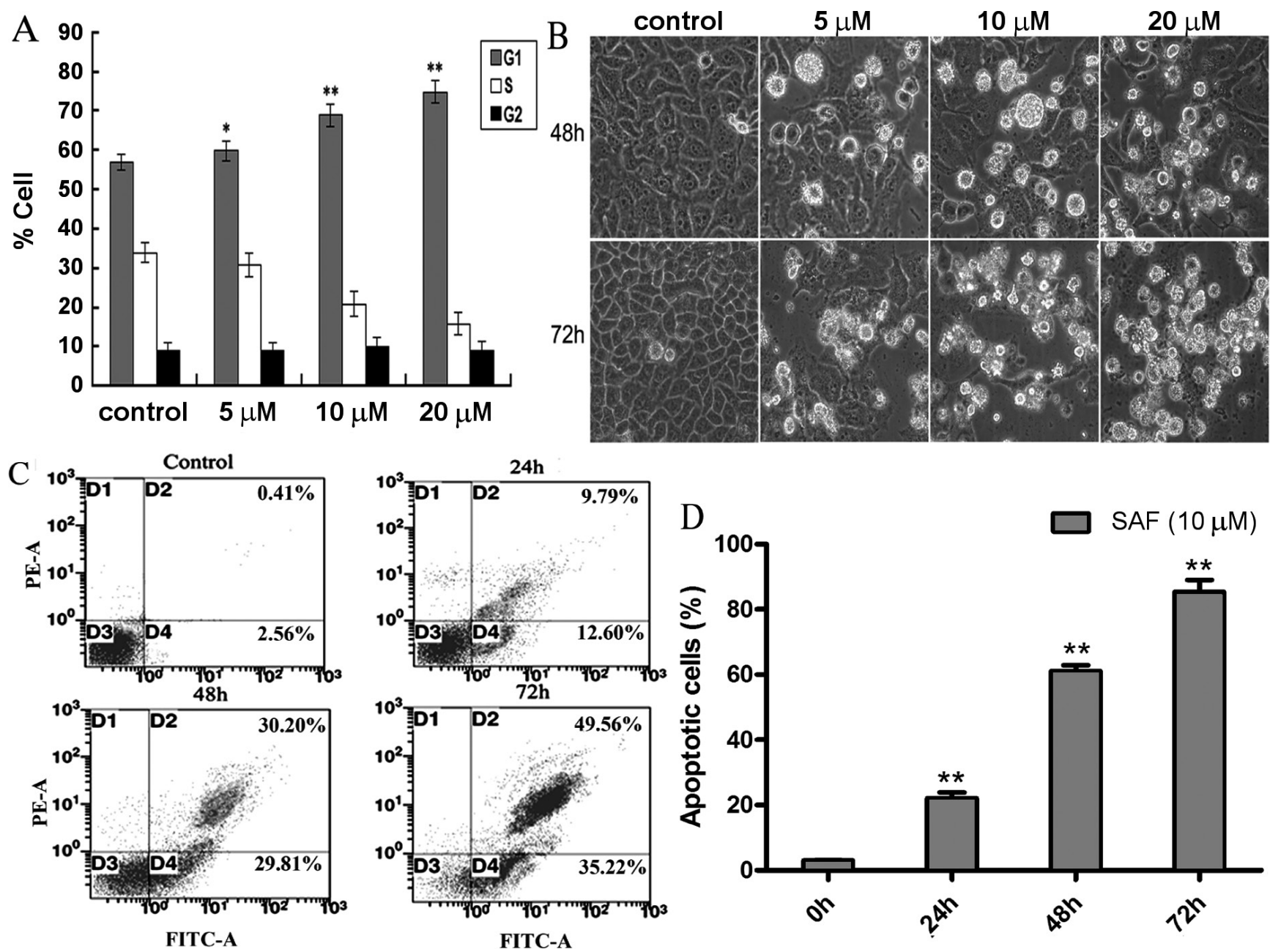

Figure 3. SAF induced cell cycle arrest and apoptosis. (A) Cells were treated with several concentrations of SAF for 48 h prior to analysis by a flow cytometer. (B) After treatment with SAF for 48 and $72 \mathrm{~h}$, the cellular morphology of the HepG2 cells were photographed under the microscope (60×). Untreated cells were performed as the negative control. (C, D) Flow cytometer analysis of PI-Annexin-V to measure apoptosis in HepG2 cells. HepG2 cells were harvested after treated with $10 \mu \mathrm{M}$ SAF for 24,48 and $72 \mathrm{~h}$. ${ }^{\star} \mathrm{P}<0.05,{ }^{\star \star} \mathrm{P}<0.01$ was considered statistically significant.

survival in extreme habitats, but also offer the potential to produce compounds for cancer and other interesting pharmacological activities. In recent years, there was a focus on the secondary metabolites of fungi derived from special environments, especially the fungi from coastal saline in the Yellow River Delta. Many novel structures with various activities were separated from them [8]. In our study, more than 400 microbial strains isolated from sediment samples that were collected from the coastal saline in the Yellow River Delta in China were screened for cytotoxicity against cancer cells. Among them, a fungal strain identified as Aspergillus aculeatus exhibited a significant cytotoxic activity. We investigated the secondary metabolites from this fungus and obtained SAF. SAF had been obtained from several sources. For example, SAF which was derived from a deep sea originated fungus Penicillium sp. F11 showed significant antitumor effects in HL60 cells [6]. This study demonstrated that SAF might have a promising inhibitory effect on cancer cell growth.

In this study, SAF significantly inhibited cell viability with a time- and concentration-manner in vitro. Most importantly, the inhibitory effect of SAF on cell viability is more potent than that of 5-FU on the same concentration. In the in vivo study, the antitumor effect of SAF was investigated in the mice xenograft model. It was obvious that SAF also significantly inhibited tumor growth with a concentration-dependent manner, and that the inhibitory effect of SAF was also easier to observe than that of 5-FU at the same concentration. This study was the first to confirm that the inhibitory effect of SAF on cancer cell growth is more promising than that of 5-FU in vitro and in vivo. Furthermore, the index of the mice's immune organs (the spleen and the thymus) and the cytotoxicities of SAF and 5-FU demonstrated that SAF might represent a better alternative to 5 -FU for clinical application in the future. 

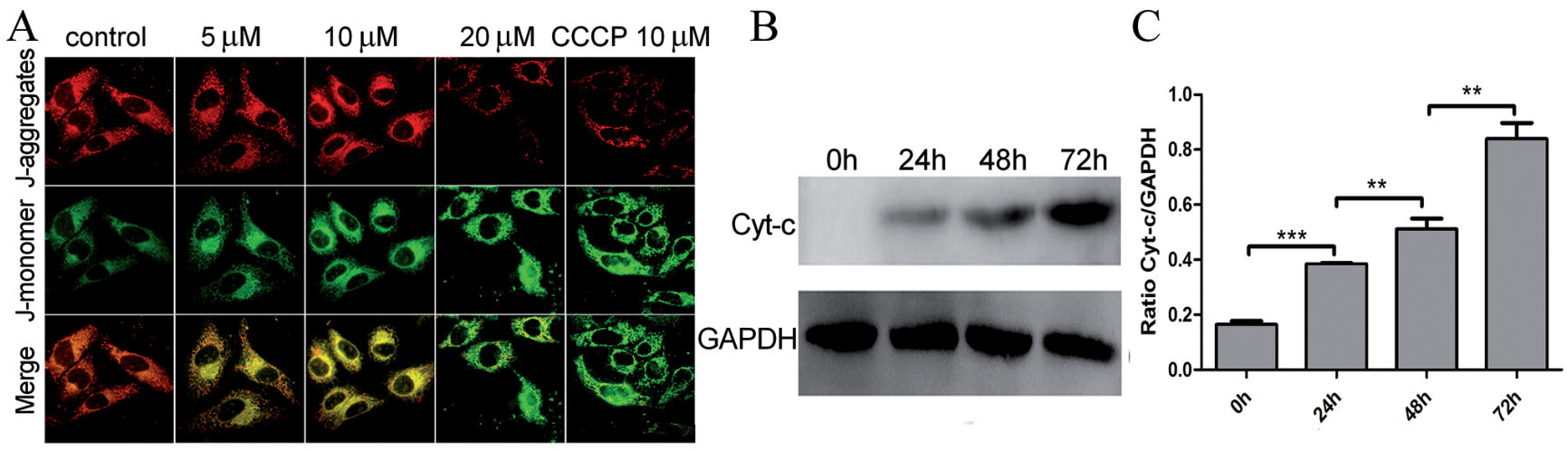

$\mathrm{D}$

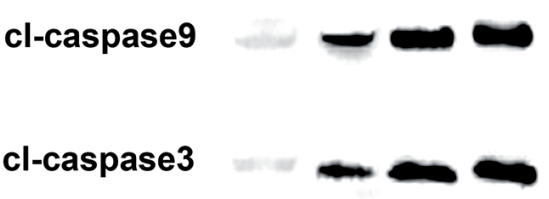

GAPDH
$\mathrm{E}$

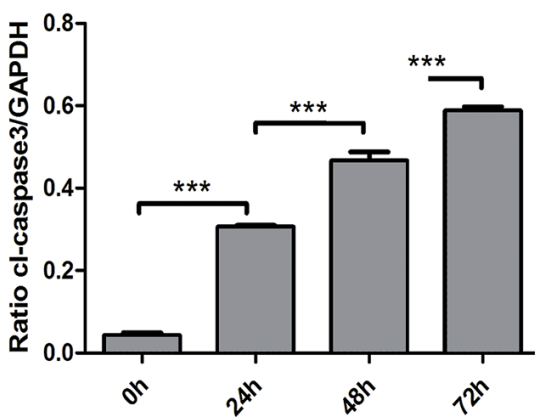

$\mathrm{F}$

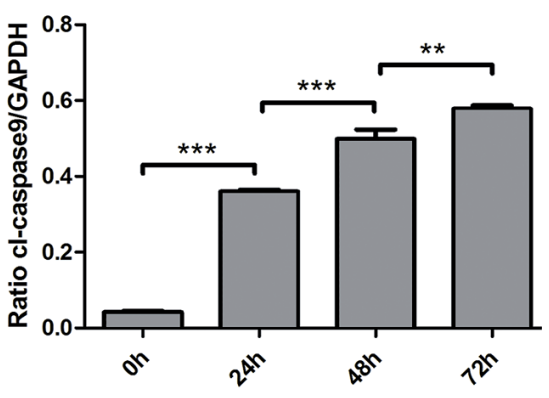

Figure 4. SAF induced apoptosis by activating caspase 3 and caspase 9 through a mitochondrial pathway. (A) Mitochondrial membrane potential ( $\Delta \Psi \mathrm{m})$ was performed with JC-1. CCCP $(10 \mu \mathrm{M})$ was used as the positive control reagent. $(\mathrm{B}, \mathrm{C})$ Expression of cytochrome $\mathrm{c}$ was assayed by western blot. (D, E, F) Western blot was performed to assay the expressions of apoptosis-related genes on protein level. Proteins of caspase 3 and caspase 9 were all cleaved fragments. GAPDH was used as a loading control. ${ }^{* *} P<0.01,{ }^{* *} P<0.001$ was considered statistically significant.

Next, we investigated the mechanisms of SAF on cell growth inhibition. The cell cycle and apoptosis may trigger cell viability delay from SAF, which caused cell cycle arrest by increasing the level of the key G2 phase and decreasing the level of the $\mathrm{S}$ phase. The microscope clearly showed that SAF induced apoptosis, which was assayed by a flow cytometer. Data showed that the mitochondrial membrane potential $(\Delta \psi \mathrm{m})$ decreased with SAF treatment, unlike the CCCP positive control group.

The activation of an intrinsic mitochondria-mediated apoptotic pathway is related to the release of cytochrome c from a mitochondrial membrane to cytosol. SAF induced the depression of cytochrome $c$ with a concentration-dependent manner. The loss of mitochondrial membrane potential $(\Delta \psi \mathrm{m})$ and the formation of Apaf-1/cytochrome c complex are important events corresponding with the activation of caspase [19, 20]. The activation of caspase family is generally considered to be one of the key events in an apoptosis pathway [21, 22]. More specially, caspase 3 and caspase 9 play the major role in the caspase-dependent pathway; thus, caspase 3 and caspase 9 activation were studied during the mechanisms of apoptosis [23, 24]. SAF induced apoptosis with a concentration-dependent manner by activating caspase-family genes, including caspase 3 and caspase9. The expressions of $\mathrm{cl}$-caspase 3 and cl-caspase 9 also increased with a concentration-dependent manner. As a result, SAF might induce apoptosis by up-regulation of cytochrome $\mathrm{c}$ in order to activate caspase 3 and caspase 9 through the mitochondrial pathway.

Overall, this study demonstrated the effects and mechanisms of SAF on hepatocellular carcinoma. In contrast to the common antitumor drug 5-FU, SAF showed more promising inhibitory effects on cell viability in vitro and tumor growth in vivo by arresting the cell cycle and inducing caspase-dependent apoptosis through a mitochondrial pathway. Consequently, SAF might be a useful antitumor agent and an effective compound in HCC clinical treatment; also, its structure might afford a promising future concerning antitumor drug investigation and design.

Acknowledgements: This study was supported by the Shandong Provincial Natural Science Foundation of China (Grant Nos. ZR2014JL055, ZR2013HL039 and ZR2013HM042) and the National Natural Science Foundation of China (Grant No. 31270082 and 81573412).

\section{References}

[1] NIU LZ, LI JL, XU KC. Percutaneous Cryoablation for Liver Cancer. J Clin Transl Hepatol. 2014; 2: 182-188. 
[2] JIE L, FAN W, WEIQI D, YINGQUN Z, LING X et al. The hippo-yes association protein pathway in liver cancer. Gastroenterol Res Pract 2013; 2013: 187070. https://doi. org/10.1155/2013/187070

[3] FERLAY J, SHIN HR, BRAY F, FORMAN D, MATHERS C et al. Estimates of worldwide burden of cancer in 2008: GLOBOCAN 2008. Int J Cancer 2010; 127: 2893-2917. https://doi. org/10.1002/ijc.25516

[4] NAGAI H, SUMINO Y. Therapeutic strategy of advanced hepatocellular carcinoma by using combined intra-arterial chemotherapy. Recent Pat Anticancer Drug Discov 2008; 3: 220-226. https://doi.org/10.2174/157489208786242296

[5] YOO BK, GREDLER R, VOZHILLA N, SU ZZ, CHEN D et al. Identification of genes conferring resistance to 5-fluorouracil. Proc Natl Acad Sci U S A. 2009; 106: 12938-12943. https:// doi.org/10.1073/pnas.0901451106

[6] LI N, YI Z, WANG Y, ZHANG Q, ZHONG T et al. Differential proteomic analysis of HL60 cells treated with secalonic acid $\mathrm{F}$ reveals caspase 3-induced cleavage of Rho GDP dissociation inhibitor 2. Oncol Rep 2012; 28: 2016-2022.

[7] ZENG R, LUO S, SHI T. Allelopathic effects of secalonic acid F produced by Aspergillus japonicus on Zea mays. Ying Yong Sheng Tai Xue Bao 2004; 15: 145-148.

[8] LIU D-S, LIU W-Z, LV Z-H. Studies on secondary metabolites of Aspergillus aculeatus derived from coastal saline soil. Chinese Journal of Marine Drugs 2014: 28-32.

[9] YANG J, LI X, XUE Y, WANG N, LIU W. Anti-hepatoma activity and mechanism of corn silk polysaccharides in $\mathrm{H} 22$ tumor-bearing mice. Int J Biol Macromol 2014; 64: 276-280. https://doi.org/10.1016/j.ijbiomac.2013.11.033

[10] GALUN D, BASARIC D, ZUVELA M, BULAJIC P, BOGDANOVIC A et al. Hepatocellular carcinoma: From clinical practice to evidence-based treatment protocols. World J Hepatol 2015; 7: 2274-2291. https://doi.org/10.4254/wjh. v7.i20.2274

[11] SIEGEL R, NAISHADHAM D, JEMAL A. Cancer statistics, 2012. CA Cancer J Clin 2012; 62: 10-29. https://doi. org/10.3322/caac.20138

[12] JEMAL A, BRAY F, CENTER MM, FERLAY J, WARD E et al. Global cancer statistics. CA Cancer J Clin 2011; 61: 69-90. https://doi.org/10.3322/caac.20107

[13] KARAMAN B, BATTAL B, SARI S, VERIM S. Hepatocellular carcinoma review: current treatment, and evidence-based medicine. World J Gastroenterol 2014; 20: 18059-18060.
[14] HU Z, LV G, LI Y, LI E, LI H et al. Enhancement of antitumor effects of 5-fluorouracil on hepatocellular carcinoma by low-intensity ultrasound. J Exp Clin Cancer Res 2016; 35: 71. https://doi.org/10.1186/s13046-016-0349-4

[15] CHENG M, HE B, WAN T, ZHU W, HAN J et al. 5-Fluorouracil nanoparticles inhibit hepatocellular carcinoma via activation of the p53 pathway in the orthotopic transplant mouse model. PLoS One. 2012; 7: e47115. https://doi. org/10.1371/journal.pone.0047115

[16] WETTERGREN Y, CARLSSON G, ODIN E, GUSTAVSSON B. Pretherapeutic uracil and dihydrouracil levels of colorectal cancer patients are associated with sex and toxic side effects during adjuvant 5-fluorouracil-based chemotherapy. Cancer 2012; 118: 2935-2943. https://doi. org/10.1002/cncr.26595

[17] JIN J, HUANG M, WEI HL, LIU GT. Mechanism of 5-fluorouracil required resistance in human hepatocellular carcinoma cell line Bel(7402). World J Gastroenterol 2002; 8: 1029-1034. https://doi.org/10.3748/wjg.v8.i6.1029

[18] HWANG JT, HA J, PARK OJ. Combination of 5-fluorouracil and genistein induces apoptosis synergistically in chemo-resistant cancer cells through the modulation of AMPK and COX-2 signaling pathways. Biochem Biophys Res Commun 2005; 332: 433-440. https://doi.org/10.1016/j. bbrc.2005.04.143

[19] KIM JY, PARK JH. ROS-dependent caspase-9 activation in hypoxic cell death. FEBS Lett 2003; 549: 94-98. https://doi. org/10.1016/S0014-5793(03)00795-6

[20] SUGIOKA R, SHIMIZU S, FUNATSU T, TAMAGAWA H, SAWA Y et al. BH4-domain peptide from Bcl-xL exerts antiapoptotic activity in vivo. Oncogene 2003; 22: 8432-8440. https://doi.org/10.1038/sj.onc. 1207180

[21] SHI Y. Mechanisms of caspase activation and inhibition during apoptosis. Mol Cell 2002; 9: 459-470. https://doi. org/10.1016/S1097-2765(02)00482-3

[22] GHOBRIAL IM, WITZIG TE, ADJEI AA. Targeting apoptosis pathways in cancer therapy. CA Cancer J Clin 2005; 55: 178-194. https://doi.org/10.3322/canjclin.55.3.178

[23] CRYNS V, YUAN J. Proteases to die for. Genes Dev 1998; 12: 1551-1570. https://doi.org/10.1101/gad.12.11.1551

[24] SHIOZAKI EN, CHAI J, RIGOTTI DJ, RIEDL SJ, LI P et al. Mechanism of XIAP-mediated inhibition of caspase-9. Mol Cell 2003; 11: 519-527. https://doi.org/10.1016/S10972765(03)00054-6 